\title{
Patient satisfaction and reported outcomes on the management of actinic keratosis
}

\section{Raveena Khanna ${ }^{1,2}$ \\ Anshika Bakshi ${ }^{3}$ \\ Yasmin Amir' \\ Gary Goldenberg'}

'Department of Dermatology, Icahn School of Medicine at Mount Sinai, New York, NY, ${ }^{2}$ Creighton University School of Medicine, Omaha, NE, ${ }^{3}$ Rutgers Robert Wood Johnson Medical School, Piscataway Township, NJ, USA
Correspondence: Gary Goldenberg Department of Dermatology, Icahn School of Medicine at Mount Sinai, 5 East 98th Street, 5th Floor, New York, NY 10029, USA

$\mathrm{Tel}+|2| 224 \mid 9728$

Fax + | 212987 | 197

Email garygoldenbergmd@gmail.com
This article was published in the following Dove Press journal:

Clinical, Cosmetic and Investigational Dermatology

17 May 2017

Number of times this article has been viewed
Abstract: Actinic keratosis (AK) is a common dermatologic condition in which hyperplastic epidermal lesions develop in response to excessive and chronic exposure to ultraviolet (UV) radiation. If left untreated, AK can progress to squamous cell carcinomas of the skin. Incidence is rising worldwide as a result of the progressive aging of populations and an increase in lifetime cumulative exposure to UV radiation. Currently, various treatment options exist, which range from topical medications to light-based therapies and procedural modalities. In this article, we will review the treatment options for AK with a focus on assessments of patient satisfaction with treatment. Keywords: actinic keratosis, treatment, outcomes, patient satisfaction, quality of life

\section{Introduction}

Actinic keratosis (AK) is a condition in which hyperplastic epidermal lesions develop in response to excessive and chronic exposure to ultraviolet (UV) radiation, which is also referred to as solar keratosis or senile keratosis. AK incidence is rising worldwide as a result of the progressive aging of populations and an increase in lifetime cumulative exposure to UV radiation. ${ }^{1}$ This sustained exposure to nonionizing radiation can result in the development of squamous cell carcinoma (SCC), as the majority of SCCs progress from preexisting AKs. ${ }^{2-4}$ Risk factors for AK include the following: Fitzpatrick Skin Types I and II (Caucasian population), gender (more common in males), age (individuals older than 30 years), geographic area (exposure to solar radiation), and immunocompromised patients. ${ }^{5}$ AK lesions thereby manifest on sun-damaged skin, enabling identification of risk groups for SCC, basal cell carcinoma, and even melanoma. ${ }^{6}$ Commonly found on sun-exposed skin, a typical primary lesion appears as a rough erythematous papule, white to yellow scaly macule, or a plaque on the face, scalp, and extremeties. ${ }^{7,8}$

Currently, various treatment options exist, which range from topical medications to light-based therapies and procedural modalities. These treatments can be grouped into two main categories: lesional therapies and field therapies. Lesional therapies, including cryotherapy and excisional therapies, are directed at individual AK lesions and are most frequently implemented when the burden of lesions is low. In contrast, field therapies, including ingenol mebutate (IM), topical imiquimod, topical 5-fluorouracil (5-FU), diclofenac sodium (DFS), and photodynamic therapy (PDT), are applied to a larger area of skin in an effort to target numerous lesions as well as subclinical disease. Although lesional therapies are localized, field therapies target a larger surface area and can also involve normal skin. The differences between these two may 
have an effect on patient tolerability and thus satisfaction. ${ }^{9}$ When drawing comparisons between the different methods, it is important to consider how method of application, cost, clinical response, and the incidence of adverse effects also contribute to the perceived success of treatment. AK has been proven to have a negative impact on patient quality of life (QoL). ${ }^{10}$ Treatment of AK is often associated with both discomfort and cosmetic impact, which may influence patient satisfaction. ${ }^{11}$ In this article, we review reported outcomes of the most commonly utilized treatments and discuss the results and methods used to assess patient satisfaction in the management of AK.

\section{Topical treatments}

Topical therapies for AK are significant because they target both visible and subclinical lesions. ${ }^{10}$ These include those nonvisible lesions that exist among the areas of damaged skin surrounding the detectable AK lesion. The damaged skin may often appear deeply wrinkled or with spotted pigmentation. Studies also reveal that there is poor adherence to topical therapies, on account of the presence of side effects and prolonged treatment. ${ }^{12-16}$

\section{IM}

IM induces rapid necrosis of dysplastic AK keratinocytes and stimulates neutrophil-mediated antibody-dependent cellular cytotoxicity (ADCC) by acting as a protein kinase $\mathrm{C}$ (PKC) agonist. ${ }^{17}$ This dual mechanism of action expedites the agent's therapeutic effect and allows for lesion destruction after a period as little as 2-3 days. ${ }^{17}$ The potential for IM to improve both outcomes and patient satisfaction has been demonstrated in various trials for the treatment of AK. A prospective pilot study examined the effects of IM gel $0.015 \%$ when applied once daily for 3 consecutive days to 28 patients with AKs of the face and observed a significant increase in QoL $(p=0.031) .{ }^{10}$ All study participants were Caucasian males, $\geq 65$ years of age, with at least seven $A K s$ on the face. The Skindex-16 survey was used at days 0 and 60 to assess patient satisfaction. This dermatologic questionnaire sought to determine the effects of AK on patient QoL in terms of symptoms, emotions, and functioning. Subjects noted their level of bothersomeness using a 0-6 numerical analog scale, ranging from "never bothered" to "always bothered." Results described a decrease in overall Skindex-16 score from 24.5 at day 0 to 15.5 at day 60 , with reductions in all three subscales. ${ }^{10}$ Statistical significance, however, was only noted in the emotions subscale $(p=0.011) .{ }^{10}$ This increase in patient QoL was consistent with a 77\% reduction in lesions
(95\% CI, 68\%-86\%). ${ }^{9}$ Furthermore, QoL seemed to improve regardless of local skin reactions (LSR) severity.

Post hoc analyses performed for four, Phase III, multicenter, randomized, double-blind, vehicle-controlled trials $(\mathrm{n}=1005)$ also revealed significant reductions in Skindex-16 bothersomeness scores $(p<0.0001)$ at day $57 .{ }^{11}$ Patients applied either IM $0.015 \%$ once daily for 3 consecutive days for the face and scalp or IM $0.05 \%$ once daily for 2 consecutive days for the trunk and extremities. ${ }^{11}$ While there was a significant association between change in overall Skindex-16 score and clearance in the face/scalp group ( $p=$ 0.0006), such was not the case in the trunk/extremities group, although there was a positive trend. ${ }^{11}$ Subjects younger than 65 years of age in the face/scalp group experienced higher QoL improvement for the emotions domain $(p=0.004)$ and for overall change in score $(p=0.024) .{ }^{11}$ The Treatment Satisfaction Questionnaire for Medication (TSQM) survey was used to evaluate effectiveness, side effects, convenience, and global satisfaction; results showed significant positive associations between TSQM score and the degree of clearance for patients in both the face/scalp group (effectiveness, $p<0.0001$ and global satisfaction, $p=0.0002)$ and the trunk/extremities group $(p<0.0001$ and $p=0.0014) .{ }^{11}$ Still greater improvements were reported for the former, which corresponded to higher efficacy rates of treatment on the face/scalp when compared to other locations.

\section{Imiquimod}

Imiquimod, a synthetic nucleoside analog of the imidazoquinoline family, activates Toll-like receptors (TLR7/8) leading to the induction of the innate immune response. ${ }^{18}$ Such a response enhances interferon (IFN), tumor necrosis factor (TNF), and interleukins 1 and 12 (IL-1/12) and further stimulates an acquired immune response through the activation of TH1 cells. ${ }^{18}$ Topical application of imiquimod induces IFN $\alpha$ within AK lesions and subsequently triggers such innate and adaptive immune response. ${ }^{19}$ An open-label, multicenter study with 118 AK patients utilized the Skindex-17 and TSQM surveys to assess how treatment with imiquimod cream 5\% impacts patient-reported outcomes and health-related QoL (HRQoL) and found no clinically relevant impact. ${ }^{20}$ However, HRQoL impairment was noted to be low even at baseline for both surveys. ${ }^{20}$ Although literature assessing patient satisfaction with imiquimod as a treatment for $\mathrm{AK}$ is limited, various studies compare patient QoL and preference between imiquimod and other treatments. A prospective, nonrandomized pilot study found that although IM had a higher median Skindex-29 score for 
convenience of therapy (83.3), both imiquimod 5\% and IM achieved higher median TSQM scores for effectiveness (72.7 for both) and global satisfaction (72.9 and 69.4, respectively) when compared to other therapies. ${ }^{21}$ Imiquimod $5 \%$ also had the highest satisfaction scores with respect to side effects (median of 93.8). ${ }^{21}$ In contrast to other topical treatments like IM, where LSR have been known to resolve by week 3, imiquimod side effects often peak during the first 2 weeks of treatment and resolve somewhere between 3-4 weeks after the therapy is complete. ${ }^{22}$ In a prospective comparative study $(\mathrm{n}=58)$ between $5 \%$ imiquimod cream and PDT with methyl aminolevulinate (MAL), patients reported no significant difference in tolerance of treatment, although $34 \%$ and $28 \%$ of patients described poor tolerance to PDT and imiquimod therapy, respectively. ${ }^{23}$ However, satisfaction evaluations, which were conducted a month after cessation of treatment, showed that a higher percentage of patients treated with PDT were very satisfied when compared to those treated with imiquimod (93\% versus $62 \%, p=0.004) .{ }^{23}$ Still, $72 \%$ of patients treated with imiquimod preferred being retreated with the same treatment. ${ }^{23}$

\section{$5-\mathrm{FU}$}

5-FU is topically applied and inhibits thymidylate synthetase, an enzyme responsible for cell death and required for DNA synthesis. ${ }^{24}$ The most common adverse effects include irritation of the skin, erythema, and dryness. ${ }^{25}$ Patient satisfaction with 5-FU has been explored in one randomized, parallel group clinical trial comparing 5\% 5-FU and 3\% DFS, as described subsequently. ${ }^{26}$

\section{DFS}

DFS is topically applied and often associated with $2.5 \%$ hyaluronic acid. Although its mechanism of action is not entirely understood, it decreases arachidonic acid metabolite formation, which would normally inhibit apoptosis and increase angiogenesis. ${ }^{27,28}$ In a randomized, parallel-group clinical trial with 28 patients of both genders with at least five AKs on the face, scalp, or back of the hands, patient satisfaction for the treatment with 5\% 5-FU and 3\% DFS was reported in terms of satisfaction with adverse effects and lesion clearance. ${ }^{26}$ Patients either applied 3\% DFS gel twice daily for 12 weeks or $5 \% 5$-FU cream twice daily for 4 weeks. As per patient testimony, $73 \%$ of those treated with DFS and $77 \%$ of those treated with 5-FU were highly satisfied, revealing no significant difference between the groups. ${ }^{26}$ However, patients treated with DFS did report significantly higher satisfaction regarding adverse events (93.3\% versus $38.4 \%, p=0.008)$, since those treated with $5-\mathrm{FU}$ observed more instances of erythema, edema, crusts, and itching. ${ }^{26}$ Patient satisfaction with lesion clearance was assessed using the Patient Global Improvement Score (unchanged, $>50 \%$ of lesions were healed, and all lesions were healed). Results show that $54 \%$ of patients treated with 5-FU reported all lesions to be healed in comparison with $20 \%$ of patients treated with DFS. ${ }^{26}$ Despite the fact that patients treated with 5-FU experienced a significantly greater reduction in the number of lesions, DFS was better tolerated. ${ }^{26}$ In a single-center, open-label, prospective, randomized controlled clinical trial of 200 patients, a comparison was drawn between treatment with diclofenac $3 \%$ plus hyaluronic acid gel (DHA) and MAL-PDT in adult Caucasian patients with skin types I-IV and at least five AKs of the face and scalp. ${ }^{1} \mathrm{~A}$ visual analog scale was used to assess pain in MAL-PDT, and patients were asked to rate satisfaction as excellent (very satisfied), good (moderately satisfied), or fair (slightly or not satisfied). Results show that more patients treated with MAL-PDT were noted being very satisfied than those treated with DHA (59\% versus $6 \%, p<0.0001) .{ }^{1}$

\section{Light therapies and procedural modalities PDT}

PDT involves the application of a photosensitizing drug to the skin surface. ${ }^{29}$ The irradiation of the accumulated photosensitizing compound leads to the production of cytotoxic oxygen species that result in cell damage. ${ }^{30}$ PDT therapy directly damages dysplastic cells, indirectly disrupts tumor vasculature, and activates an inflammatory response characterized by localized edema at the target site. ${ }^{31,32}$ Although there is a general lack of literature assessing patient satisfaction as it pertains to various treatment options for AK, the majority of information that does exist pertains to treatment with either IM or PDT. In a retrospective telephone survey of 24 patients with facial or scalp AK, 50\% of patients thought PDT was very effective. ${ }^{33}$ Patients selected for this study had PDT field therapy using either $160 \mathrm{mg} / \mathrm{g}$ MAL cream or generic compound 20\% 5-aminolavulinic acid (5-ALA) solution. Pain during illumination was reported as a significant problem, with $58 \%$ of patients reporting severe pain. ${ }^{33}$ Although $50 \%$ of respondents reported high efficacy, $70 \%$ of patients found PDT to be barely affordable. ${ }^{33}$ Still, $66 \%$ of respondents said they would recommend PDT to others..$^{33}$ Among those who said they would not recommend the treatment were those patients who experienced moderate to severe side effects and those who were disappointed with their clearance relative to cost and pain.

In a Phase III, multicenter, randomized, investigatorblinded, controlled, intraindividual study that lasted 12 weeks, 
daylight PDT (DL-PDT) was compared to conventional PDT (c-PDT), revealing an instance where pain seemed to directly influence patient satisfaction. ${ }^{34}$ Clinical trials support the success of c-PDT in effectively treating AK, especially in patients with AKs covering larger areas. ${ }^{35}$ However, trials have found that c-PDT is associated with significant pain, especially when treating the face. ${ }^{36}$ Growing literature also asserts that DL-PDT is less painful in comparison, on account of its different photoactivation. ${ }^{34}$ Results of the trial of 108 subjects describe DL-PDT to be virtually painless compared to c-PDT ( 0.7 versus $4.4, p<0.001)$, which was consistent with better tolerance and higher satisfaction for DL-PDT. ${ }^{34}$ Overall, $64.8 \%$ of subjects were very satisfied with DL-PDT compared to $18.9 \%$ with c-PDT. More patients found DL-PDT to be very convenient when compared to those treated with c-PDT (53.8\% versus $10.5 \%$, respectively).

In another study, a questionnaire was mailed to 39 subjects, surveying for factors such as cost, effectiveness, treatment preference between PDT, 5-FU, and imiquimod as options, recovery time, and overall patient satisfaction. ${ }^{37}$ Patients significantly preferred PDT to 5-FU $(p<0.001)$ and imiquimod ( $p=0.031)$, and recovery time for PDT was 1 week or less when compared to cryotherapy $(p=0.02)$ and surgical excision $(p=0.02)$.

\section{Cryotherapy}

Cryotherapy is one of the most commonly used AK treatments and is performed by freezing individual $\mathrm{AK}$ lesions with liquid nitrogen delivered at $-195.8^{\circ} \mathrm{C} .{ }^{37}$ Epidermal keratinocytes, which characteristically die at $-40^{\circ} \mathrm{C}$ to $-50^{\circ} \mathrm{C}$, are destroyed by this freezing approach. ${ }^{38}$ This quick and relatively simple therapeutic strategy is a common first-line approach for AK treatment. ${ }^{39}$ In a multicenter randomized, intraindividual (right-left) study, 119 subjects from both genders participated in telephone calls at weeks 1 and 13 to assess patient overall preference and lesion response to cryotherapy in comparison with MAL-PDT. ${ }^{40}$ Patient satisfaction was recorded on a five-point scale that ranged from 1 (very dissatisfied) to 5 (very satisfied). Results showed that patients preferred MAL-PDT to cryotherapy (49.2\% versus $20.6 \%, p<0.001$ ), with $>90 \%$ satisfied with MAL-PDT for effectiveness and scarring. ${ }^{40}$ Still, $91.7 \%$ preferred cryotherapy to MAL-PDT with regard to the prolonged duration of treatment. ${ }^{40}$

In another similar study lasting 24 weeks, $59 \%$ of patients $(\mathrm{n}=121)$ preferred their new lesions to be treated with MAL-PDT, which was significantly higher than the $25 \%$ that preferred cryotherapy $(p<0.001) .{ }^{41}$ However, there was no significant difference between the two treatment options in terms of patient perception of effectiveness. MAL-PDT was preferred to cryotherapy for comfort $(60 \%$ versus $10 \%, p$ $<0.001)$, healing outcome $(64 \%$ versus $6 \%, p<0.001)$, and overall patient satisfaction ( $49 \%$ versus $20 \%, p<0.001)$. Consistent with other findings, cryotherapy resulted in $20 \%$ more skin-related adverse events when compared to MAL-PDT. ${ }^{42}$

\section{Conclusion}

When assessing patient-perceived outcomes and management of AK, patient satisfaction and QoL are often used interchangeably. However, current literature discussing improvement in QoL is limited to either retrospective or observational studies and varies widely in terms of quantifiable criteria for satisfaction assessments (Supplementary material).${ }^{10}$ It is difficult to quantify patient satisfaction on account of the many factors that influence patient perception of treatment outcome and QoL. These factors include age, gender, location of lesions, cost, duration of treatment, adverse effects, tolerance, and efficacy. A small patient population or a homogeneous subject group in terms of race, age, and gender can therefore skew results. Oftentimes, patient satisfaction reflects a balance between these factors, a claim consistent in current findings. ${ }^{10}$

Although there is a lack of literature assessing QoL specifically, current studies underscore the importance of pain, lesion clearance, and adverse effects to overall satisfaction scores. Pain may contribute to both treatment tolerance and adherence. Recent findings state that short-term therapies with prompt clearance of AEs promote adherence of treatment and are therefore preferred. ${ }^{43}$ In many instances, patients may even opt to use the less effective treatment if they feel the other options are intolerable. Such was the case with patients who preferred cryotherapy to PDT and imiquimod. ${ }^{23}$

When comparing patient satisfaction between different AK treatments, it is also important to parallel the various types of surveys used to quantify QoL. Among the studies discussed, telephone interviews were often utilized, as were the Skindex and TSQM surveys. In contrast to the Dermatology Life Quality Index (DLQI), the Skindex-16 dermatology survey mostly evaluates clinical severity and the TSQM evaluates satisfaction with the medication. ${ }^{44}$ The DLQI also fails to assess factors such as fear of SCC, which would potentially show in the emotions subscale of the Skindex-16 survey. Still, it is questionable whether these surveys effectively capture fears such as that of recurrence. As a chronic disease, AK requires repeated treatments, especially during the second half of a patient's lifetime. ${ }^{34}$ As such, it may even be useful to assess satisfaction by determining how willing patients are to repeat certain treatments and compare these numbers to 
those who are unwilling. Although literature on patient satisfaction is lacking for various $\mathrm{AK}$ treatment options, based on the studies that do exist, PDT and IM have the highest QoL ratings among patients.

\section{Disclosure}

Raveena Khanna, BA, Anshika Bakshi, BS, and Yasmin Amir, $\mathrm{BA}$, have no relevant conflicts of interest to disclose in this work. Gary Goldenberg, MD is a consultant, investigator, and speaker for LEO Pharma, PharmaDerm, and Valeant Pharmaceuticals International, Inc. The authors report no other conflicts of interest in this work.

\section{References}

1. Zane C, Facchineeti E, Rossi MT, Specchia C, Calzavara-Pinton PG. A randomized clinical trial of photodynamic therapy with methyl aminolaevulinate vs. diclofenac 3\% plus hyaluronic acid gel for the treatment of multiple actinic keratoses of the face and scalp. Br J Dermatol. 2014; 170(5):1143-1150.

2. Ackerman AB, Mones JM. Solar (actinic) keratosis is squamous cell carcinoma. Br J Dermatol. 2006;155(1):9-22.

3. Anwar J, Wrone DA, Kimyai-Asadi A, Alam M. The development of actinic keratosis into invasive squamous cell carcinoma: evidence and evolving classification schemes. Clin Dermatol. 2004;22(3):189-196.

4. Criscione VD, Weinstock MA, Naylor MF, et al; Department of Veteran Affairs Topical Tretinoin Chemoprevention Trial Group. Actinic keratoses: natural history and risk of malignant transformation in the Veterans Affairs Topical Tretinoin Chemoprevention Trial. Cancer. 2009;115(11):2523-2530.

5. Ramos e Silva M, Castro MCR. Fundamentos de dermatologia. 1 ed. São Paulo: Ateneu; 2009.

6. Salache SJ. Epidemiology of actinic keratoses and squamous cell carcinoma. J Am Acad Dermatol. 2000;42(1 pt 2):4-7.

7. Bolognia JL, Jorizzo JL, Rapini RP. Dermatology. 2nd ed. Rio de Janeiro: Elsevier; 2008.

8. Rapini RP. Dermatopatologia prática. Rio de Janeiro: Di Livros; 2007.

9. Ceilley RI, Jorizzo JL. Current issues in the management of actinic keratosis. J Am Acad Dermatol. 2013;68(1 suppl 1):S28-S38.

10. Emilio J, Schwartz M, Feldman E, et al. Improved patient satisfaction using ingenol mebutate gel $0.015 \%$ for the treatment of facial actinic keratoses: a prospective pilot study. Clin Cosmet Investig Dermatol. 2016;9:89-93.

11. Augustin M, Tu JH, Knudsen KM, Emtoft S, Larsson T, Hanke CW. Ingenol mebutate gel for actinic keratosis: the link between quality of life, treatment satisfaction, and clinical outcomes. J Am Acad Dermatol. 2015;72(5):816-821.

12. Hadley J, Tristani-Firouzi P, Hull C, Florell S, Cotter M, Hadley M. Results of an investigator-initiated single-blind split-face comparison of photodynamic therapy and 5\% imiquimod cream for the treatment of actinic keratoses. Dermatol Surg. 2012;38:722-727.

13. Shergill B, Zokaie S, Carr AJ. Non-adherence to topical treatments for actinic keratosis. Patient Prefer Adherence. 2013;8:35-41.

14. Steinbauer J, Koller M, Kohl E, Karrer S, Landthaler M, Szeimies R-M. Quality of life in health care of non-melanoma skin cancer - results of a pilot study. J Dtsch Dermatol Ges. 2011;9(2):129-135.

15. Gholam P, Kroehl V, Enk AH. Dermatology life quality index and side effects after topical photodynamic therapy of actinic keratosis. Dermatology. 2013;226(3):253-259.

16. Esmann S, Vinding GR, Christensen KB, Jemec GBE. Assessing the influence of actinic keratosis on patients' quality of life: the AKQoL questionnaire. Br J Dermatol. 2013;168(2):277-283.

17. Alchin DR. Ingenol mebutate: a succinct review of a succinct therapy. Dermatol Ther (Heidelb). 2014;4(2):157-164.
18. Urosevic M, Maier T, Benninghoff B, Slade H, Burg G, Dummer R. Mechanisms underlying imiquimod-induced regression of basal cell carcinoma in vivo. Arch Dermatol. 2003;139(10):1325-1332.

19. Torres A, Storey L, Anders M, et al. Immune-mediated changes in actinic keratosis following topical treatment with imiquimod $5 \%$ cream. J Transl Med. 2007;5:7-7.

20. Waalboer-Spuij R, Holterhues C, van Hattem S, et al. Patient perception of imiquimod treatment for actinic keratosis and superficial basal cell carcinoma in 202 patients. Dermatology. 2015;231(1):56-62.

21. Jubert-Esteve E, Del Pozo-Hernando LJ, Izquierdo-Herce N, BauzáAlonso A, Martín-Santiago A, Jones-Caballero M. Quality of life and side effects in patients with actinic keratosis treated with ingenol mebutate: a pilot study. Actas Dermosifiliogr. 2015;106(8):644-650.

22. Kopera D, Visualization Kerl H. Treatment of subclinical actinic keratoses with topical imiquimod 5\% cream: an observational study. Biomed Res Int. 2014;2014:1-4.

23. Serra-Guillen C, Nagore E, Hueso L, et al. A randomized comparative study of tolerance and satisfaction in the treatment of actinic keratosis of the face and scalp between 5\% imiquimod cream and photodynamic therapy with methyl aminolaevulinate. Br J Dermatol. 2011; 164(2):429-433.

24. de Berker D, McGregor JM, Hughes BR; British Association of Dermatologists Therapy Guidelines and Audit Subcommittee. Guidelines for the management of actinic keratoses. Br J Dermatol. 2007;156(2):222-230.

25. Tutrone WD, Saini R, Caglar S, Weinberg JM, Crespo J. Topical therapy for actinic keratoses, I: 5-fluorouracil and imiquimod. Cutis. 2003; 71:365-370.

26. Segatto MM, Dornelles SI, Silveira VB, Frantz Gde O. Comparative study of actinic keratosis treatment with 3\% diclofenac sodium and 5\% 5-fluorouracil. An Bras Dermatol. 2013;88(5):732-738.

27. Del Rosso JQ. New and emerging topical approaches for actinic keratoses. Cutis. 2003;72(273-6):279.

28. Tutrone WD, Saini R, Caglar S, Weinberg JM, Crespo J. Topical therapy for actinic keratoses, II: diclofenac, colchicine, and retinoids. Cutis. 2003;71(5):373-379.

29. Neville JA, Welch E, Leffell DJ. Management of nonmelanoma skin cancer in 2007. Nat Clin Pract Oncol. 2007;4(8):462-469.

30. Szpringer E, Lutnicki K, Marciniak A. Photodynamic therapy mechanism and employment. Ann Univ Mariae Curie Sklodowska Med. 2004;59(2):498-502.

31. Lucena SR, Salazar N, Gracia-Cazana T, et al. Combined treatments with photodynamic therapy for non-melanoma skin cancer. Int $\mathrm{J} \mathrm{Mol}$ Sci. 2015;16(10):25912-25933.

32. Agostinis P, Berg K, Cengel KA, et al. Photodynamic therapy of cancer: an update. CA Cancer J Clin. 2011;61(4):250-281.

33. Tran DT, Salmon R. Field treatment of facial and scalp actinic keratoses with photodynamic therapy: survey of patient perceptions of treatment satisfaction and outcomes. Australas J Dermatol. 2011;52(3): 195-201.

34. Lacour JP, Ulrich C, Gilaberte Y, et al. Daylight photodynamic therapy with methyl aminolevulinate cream is effective and nearly painless in treating actinic keratoses: a randomised, investigator-blinded, controlled, phase III study throughout Europe. J Eur Acad Dermatol Venereol. 2015;29(12):2342-2348.

35. Sidoroff A, Thaler P. Taking treatment decisions in non-melanoma skin cancer-the place for topical photodynamic therapy (PDT). Photodiagnosis Photodyn Ther. 2010;7(1):24-32.

36. Wiegell S, Hædersdal M, Philipsen P, Eriksen P, Enk CD, Wulf HC. Continuous activation of PpIX by daylight is as effective as and less painful than conventional photodynamic therapy for actinic keratoses; a randomized, controlled, single-blinded study. $\mathrm{Br} J$ Dermatol. 2008;158(4):740-746.

37. Tierney EP, Eide MJ, Jacobsen G, Ozog D. Photodynamic therapy for actinic keratoses: survey of patient perceptions of treatment satisfaction and outcomes. J Cosmet Laser Ther. 2008;10(2):81-86.

38. Dodds A, Chia A, Shumack S. Actinic keratosis: rationale and management. Dermatol Ther (Heidelb). 2014;4(1):11-31. 
39. Chetty P, Choi F, Mitchell T. Primary care review of actinic keratosis and its therapeutic options: a global perspective. Dermatol Ther (Heidelb). 2015;5(1):19-35.

40. Morton C, Campbell S, Gupta G, et al; AKtion Investigators. Intraindividual, right-left comparison of topical methyl aminolaevulinate-photodynamic therapy and cryotherapy in subjects with actinic keratoses: a multicentre, randomized controlled study. Br J Dermatol. 2006;155(5):1029-1036.

41. Kaufmann R, Spelman L, Weightman W, et al. Multicentre intraindividual randomized trial of topical methyl aminolaevulinate-photodynamic therapy vs. cryotherapy for multiple actinic keratoses on the extremities. Br J Dermatol. 2008;158(5):994-999.
42. Freeman M, Vinciullo C, Francis D, Spelman L. A comparison of photodynamic therapy using topical methyl aminolaevulinate (Metvix) with single cycle cryotherapy in patients with actinic keratosis: a prospective, randomized study. J Dermatolog Treat. 2003;14: 99-106.

43. Stockfleth E, Peris K, Guillen C, et al. Physician perceptions and experience of current treatment in actinic keratosis. J Eur Acad Dermatol Venereol. 2015;29(2):298-306.

44. Chren MM, Lasek RJ, Sahay AP, Sands LP. Measurement properties of Skindex-16: a brief quality-of-life measure for patients with skin diseases. J Cutan Med Surg. 2001;5(2):105-110.

\section{Publish your work in this journal}

Clinical, Cosmetic and Investigational Dermatology is an international, peer-reviewed, open access, online journal that focuses on the latest clinical and experimental research in all aspects of skin disease and cosmetic interventions. This journal is included on PubMed. The manuscript management system is completely online and includes a very quick and fair peer-review system, which is all easy to use. Visit http://www.dovepress.com/testimonials.php to read real quotes from published authors 